\title{
Author Correction: Skill levels and gains in university STEM education in China, India, Russia and the United States
}

Prashant Loyalka (D), Ou Lydia Liu (D), Guirong Li, Elena Kardanova (D), Igor Chirikov (D), Shangfeng Hu, Ningning Yu (D), Liping Ma, Fei Guo (D), Tara Beteille, Namrata Tognatta, Lin Gu(D), Guangming Ling (D), Denis Federiakin (D), Huan Wang (D), Saurabh Khanna (D), Ashutosh Bhuradia (D), Zhaolei Shi (iD and Yanyan Li

Correction to: Nature Human Behaviour https://doi.org/10.1038/s41562-021-01062-3, published online 1 March 2021.

In the version of this article initially published, the last sentence of the first paragraph in the Results section "Critical thinking skills levels and gains" should have read, "However, by the end of their fourth year, while students in China still scored much higher than students in India (0.973 s.d., $P<0.001,95 \% \mathrm{CI}=0.661-1.286)$, their scores were statistically indistinguishable from students in Russia $(-0.053$ s.d., $P=0.780,95 \% \mathrm{CI}=-0.431-0.324)$, and much lower than year 4 students in the United States $(-1.173$ s.d., $P<0.001,95 \% \mathrm{CI}=$ -1.654 to -0.692$)$."

Additionally, in the Methods section "Sampling, exam administration and analysis for the United States" the sentences beginning "In terms of Carnegie classifications..." should have read "In terms of Carnegie classifications, the sample includes 12 Doctoral research institutions ( 1035 students or $65 \%$ of the sample), 22 Masters institutions (473 students or $30 \%$ of the sample) and 9 Baccalaureate institutions (90 students or $6 \%$ of the sample). Approximately $45 \%$ of the sampled students were in fact from the highest ranking R1 institutions-Doctoral universities, institutions with the highest research activity" The third sentence of the following paragraph should have stated that equivalent scores were available for $51 \%$ of the sample." The original description was based on the preliminary set of US data that had not been updated before submission. The sample actually used for this study is, in fact, larger and more representative. The errors have been corrected in the PDF and HTML versions of this article.

Published online: 6 April 2021

https://doi.org/10.1038/s41562-021-01102-y

(C) The Author(s), under exclusive licence to Springer Nature Limited 2021 